\title{
VOCATIONAL APTITUDE FOR YOUNG UNEMPLOYED
}

\author{
Francisco Manuel Morales Rodríguez \\ University of Malaga, Spain \\ E-mail: framorrod@uma.es
}

\begin{abstract}
The aim of this study is presenting the structure and fundamental characteristics of a Mixed Experience Program Training and Employment whose overall objective was to introduce teenagers who live in rural areas by providing training activities necessary for this. This study provides an assessment of the impact and satisfaction of certain educational activities has had on the students participating in this program as protagonists of the teaching/learning. Participants were 40 students, aged between 16 and 24 years old in rural areas of the province of Málaga, without previous employment and without qualification. The data show that the program has been a successful experience that has helped to facilitate labour insertion of participating pupils. The data show positive attitudes in students towards the use of new technologies like the Internet to facilitate their learning and that most of the activities they have been very satisfactory.

Key words: career counselling, educational activities, sociolaboral insert, teenagers.
\end{abstract}

\section{Introduction}

In the days in which we live, in full adaptation to the European Higher Education must be more aware than ever of the importance of proper vocational guidance, as well as the enormous benefits of such initiatives and programs have on the population in particular, socio-culturally disadvantaged groups on those who in times of crisis are even more vulnerable. It is necessary to introduce teenagers who live in rural areas into the labour world, providing them the necessary formative activities. Mixed Experience Program Training and Employment (EMFE) was a successful experience that facilitated the sociolaboral insert of this socioculturally disadvantage collective.

EMFE is a successful program that somehow confirms how public policy should be directed specifically towards the promotion of such programs in two directions: On one hand, be improved by training as that given in the preparation for this program active life. On the other hand, lay down measures designed to facilitate social and occupational integration and the promotion of tutoring, educational, and personal attention driven up in this program during the development of professional practice.

Next, it is necessary, bring the general and specific objective of the program implemented. In this program alternated theory with practice in each module, so that the end of the course the student has achieved the knowledge and practice enough to start exercising the profession learned.So the overall objective of the program was to introduce young people and adolescents living in rural communities in the province of Malaga in the workplace, giving them a complete overview of both the physical environment as possible as the current employment problems and obtain a better position compared to the labor market, and get as far as possible a higher degree of employability which until then had one hand, and on the other hand, they unveiled the latest trends and techniques and innovative in professions that were given.

The specific objectives of EMFE were: 1) To contribute to this project the students acquire 
PROBLEMS

OF EDUCATION

IN THE $21^{\text {st }}$ CENTURY

Volume 44, 2012

knowledge and practical skills required to access any of the formulas of self-employment or existing paid employment, 2) Provide a integral training students / as combining theoretical knowledge about these specialized educational and skills to develop productive work via practical activities; 3) Determine the resources, the prospects of employment, interests, social and employment situation, motivation, skills, abilities, knowledge and skills of students, which was the basis for the proposed social and occupational integration, 4) Conduct and plan for the duration program orientation activities to facilitate social and occupational integration of participating pupils, by the employability plan most appropriate for each student / a personally, related to the labor market to realize their career goal. Once determined it followed a path to achieve the target set; 5) Promote the use of local resources consistent with the improvement of the urban environment, community services and the environment, 6) Generate added value in rural areas.

An important consideration in this area of educational guidance (consistent with the importance that is currently occurring in the said model of intervention through technological resources) is that concerning the relationship between training, employment and new technologies. There are many advantages and contributions that digital technologies can have on the world of orientation today. In this line, a point to note is that mass access to the Information Technology and Communication (ICT) is changing our conception of time.

One of the important elements in the process of integration of ICT in this program is to know exactly the views and attitudes of students regarding the use of ICT in the learning process and integration (De Pablos, 2009; Martinez Aguaded, 2004; Trujillo, 2005). Specifically, this study analyzed the results of the questionnaire, "Attitudes and interests towards ICT" which was answered by the participants in this program.

For all the above, the overall objective of this study is to find out how people from Malaga perceive EMFE, which introduced young people and teenagers who live in rural villages in the workplace. In order to achieve this general objective, the survey results provide attitudes and interests towards ICT completed by students participating in the Program as an important element EMFE before making use of various technological means to facilitate the insertion process employment consistent with the current technological model. It also presents an evaluation of the impact and satisfaction they have had educational activities in the students participating in the program as the true stars of the teaching / learning as well as what were the main activities and achievements of social and occupational integration achieved.

\section{Problem of Research}

In full adaptation to the European Higher Education we must be more aware than ever of the importance of proper vocational guidance, as well as the enormous benefits of such initiatives and programs have on the population in particular, socio-culturally disadvantaged groups on those who in times of crisis are even more vulnerable. In this study we have presented the structure and fundamental characteristics of the successful EMFE Program which has been a successful experience that has helped to facilitate labour insertion of participating pupils. This study provides an assessment of the impact and satisfaction of certain educational activities has had on the students' participating in this program as protagonists of the teaching/ learning. 


\section{Methodology of Research}

General Background of Research

In this study is presented the program EMFE that was conducted during the academic years: $2002 / 2003$ and 2003/2004. The overall objective of the program was to introduce young people and adolescents living in rural communities in the province of Malaga in the workplace. In both courses the teaching methodology was adapted to each course module in terms of skills, knowledge and relevant skills, ie providing feedback at the right time at the same time improved the motivation of everyone involved in them.

\section{Sample of Research}

The total number of students participating in the program was 40 , with a total of three training specialties aged between 16 and 24 years of age and rural areas of the province of Malaga. Among the characteristics of the participants are the fact that young people under 25 years without previous employment and without qualification. As a general statistical data about the gender variable are extracted: the $46.67 \%$ are male students and $53.33 \%$ are female students. There are some young people with Special Educational Needs (15\%) and in some of these young people, especially children, can detect a deficit in social skills. With regard to participant characteristics can be noted that they all possess the level of education as primary school certificate, diploma or bachelor GBS without elemental, are already 16 years old and are also academically unmotivated to continue their studies in formal education. We can stand out that the composition of the sample is balanced by gender and that the majority of participants are aged between 17 and 20 years. The criteria used for selection were the following: meeting the minimum age (16-24 years) as from the 25 if they could join other workshops or schools workshop employment, educational level has indicated with respect to their professional knowledge to be First Job Claimants under 25 years (registered in the corresponding Employment Service). This program was a selection of participating students considering interests, expectations, educational needs and other indicators of risk and vulnerability to social exclusion. Priority was given to the participation of socially and culturally disadvantaged groups that have fewer opportunities for training that were awarded grants by the Andalusian Employment Service for their participation in the program. In fact, conditions were to be preferred immigrants, disabled, victims of gender violence or belong to ethnic minorities or dysfunctional families at higher risk of social exclusion.

\section{Instrument and Procedures}

"Questionnaire 'attitudes and interests towards ICT": This instrument was developed by the research group PAI HUM 378 of Andalusia. Presents adequate psychometric properties and has been used in numerous studies and research such as those by Morales, Infante and Galindo (2003). This instrument was answered by the participants in this program. The issues reflected in the questionnaire refer to what is known at the computer, how young people feel useful Internet, from where are accessed, how often and how far they consider it useful to use the viewing of videos, PowerPoint, etc. in the process of learning and social and occupational integration as well as numerous issues on which they are asked what are the functions that the Internet can have in an educational context, especially to facilitate their social and occupational integration. They were used as far as possible new technologies not only in each of the specialties but, for example, Internet for job search, especially considering the particular motivating this technological resource for students of these ages. This explains 
PROBLEMS

OF EDUCATION

IN THE $21^{\text {st }}$ CENTURY

Volume 44, 2012

the need to use this questionnaire-to-assess-these-aspects. In order to assess the potential applications of the Internet in the educational context, a Likert scale was used to measure to what degree students agree with a number of statements, ranging from $0=$ nothing $1 ; 1=\mathrm{a}$ little, $2=$ enough, $3=\mathrm{a}$ lot. The questionnaire presents adequate psychometric properties.

"Evaluation End of Training Action": In addition to continuous monitoring and evaluation investigating in details of both the content and the training situation, we performed an "Assessment End Training Action" at the end of the teaching modules as well as evaluation the development of vocational training courses. Specifically, this work has used the Inventory and Assessment Trainer Course (Finkbeiner, Lathrop and Schuelger, 1973). This instrument consists of 42 items to answer on a scale of 5 Steps (Strongly Agree, Agree, Neutral, Disagree and Strongly Disagree). Although this study only presents the most relevant and meaningful results regarding the same items, the questionnaire allows assessing five factors such as general attitude towards the course, attitude tests, attitude toward the method, ratio trainer / student and attitude to workload (competencies).

This instrument has been used in numerous investigations and has adequate psychometric properties, reliability and validity (Cohen, 1981; Marsh, Overall, and Kesler, 1979). With respect to such "evaluation EMFE Program" is considered knowledge, procedures and attitudes. Finally, for the evaluation of work experience in the development of mixed experiences programs and employment training "was also carried out a qualitative assessment by face and telephone interviews of teachers and students of the course. This also asked teachers to evaluate the course to students about issues such as: a) Technical capacity: For example, if the student is able to perform the activities assigned; b) Organisational capabilities: For example, if you attend punctually at the workplace; c) relational capabilities: For example, if you ask for information and help when needed; d) Capacity to respond to contingencies: for example, provides solutions and ideas to the problems, and so on.

For completing the questionnaires, young people were informed about the privacy of information and the need to respond individually and anonymously at the time a boy / need these tests to assess their level of satisfaction with the development the program. To administer the various tests (questionnaires, telephone interview, etc.) reported to the family and students about the voluntary nature of participation, ensuring at all times the confidentiality of the data by global treatment. The application was developed by a counsellor who explained the objectives of the faculty giving appropriate instructions to the students. This questionnaire presents adequate psychometric properties. The questionnaires were collectively spent in the different specialties in the same order of test administration.

\section{Data Analysis}

The program was conducted during the academic years: 2002/2003 and 2003/2004. In times of crisis it is important to present these results. In both courses the teaching methodology was adapted to each course module in terms of skills, knowledge and relevant skills, ie providing feedback at the right time at the same time improved the motivation of everyone involved in them. Specific websites were accessed for both job search related to the specialty to complete the content based on the case. In any case, the instructions were planned, systematic and directed.

\section{Results of Research}

Attitudes and interests towards ICT: Below are the most significant results of the questionnaire used to ascertain the attitudes and interests towards the use of ICT in the educational activities of socio-made training and guidance in this program (Table 1). 
Table 1. Internet attitudes and interest in the participants (EMFE) (\%).

\begin{tabular}{|c|c|c|}
\hline \multirow{2}{*}{ Do you Know what is the Internet? } & No & 15 \\
\hline & Yes & 85 \\
\hline \multirow[t]{5}{*}{ You know Internet through : } & Friends & 30 \\
\hline & School & 40 \\
\hline & Family & 10 \\
\hline & Television & 19 \\
\hline & Other possibilities & 1 \\
\hline \multirow{2}{*}{ Have you computer? } & Yes & 8 \\
\hline & No & 92 \\
\hline \multirow{5}{*}{ Access from: } & High School & 3.76 \\
\hline & University & 0 \\
\hline & Internet cafe & 4.76 \\
\hline & Home & 61.90 \\
\hline & Job or others & 5 \\
\hline \multirow{2}{*}{ The frequency that you use it: } & 1 or + times/day & 92 \\
\hline & 1 or + times/week & 8 \\
\hline \multirow{5}{*}{ Services: } & Email & 50.40 \\
\hline & Chat & 17.83 \\
\hline & Forum & 1 \\
\hline & Searcher & 30.77 \\
\hline & Others & 0 \\
\hline \multirow{2}{*}{ Web page: } & Yes & 0 \\
\hline & No & 100 \\
\hline \multirow{2}{*}{ Can you create an Internet addiction? } & Yes & 60 \\
\hline & No & 40 \\
\hline \multirow{2}{*}{ Can be and educational resources? } & Yes & 91 \\
\hline & No & 9 \\
\hline
\end{tabular}

Most of the students participating in the program known EMFE Internet (Table 1). Likewise, when asked how they knew? About $40 \%$ of respondents claim that they met through the school and the rest through friends, family, and through television. Most personal computer does not have and has no website. The most used Internet service when accessing the network are in order of use: mail $(50.40 \%)$, search engines $(30.00 \%)$, chats $(17.83 \%)$ forums $(1 \%)$. The vast majority $(91.00 \%)$ believe that the Internet could be used as a teaching resource. Regarding the degree in which they find useful to use video views for easy learning and social and occupational integration process mean score on a scale of 0-10 was 9.57. Also award a score of 8.9 to the extent that it useful to use PowerPoint in lectures as well as a score of 9.2 the extent to which they like to use it.

They claim these participants, generally speaking, computer skills are at the user level in terms of word processors, databases, spreadsheets and the Internet, while not claiming to have knowledge of graphic design, animation and programming. The summary data with the 
PROBLEMS

OF EDUCATION

IN THE $21^{\text {st }}$ CENTURY

Volume 44, 2012

58 corresponding percentages on some of the knowledge of participants in the program EMFE are presented in Table 2.

Table 2. General knowledge of standard computer.

\begin{tabular}{|c|c|c|c|}
\hline & \multicolumn{3}{|c|}{ \% level } \\
\cline { 2 - 4 } & Not have & User level & 7 \\
\hline Word processors & 0 & 93 & 0 \\
\hline Database & 48.22 & 51.78 & 0 \\
\hline Spreadsheets & 60.48 & 39.52 & 0 \\
\hline Internet & 0 & 100 & 0 \\
\hline Graphic design & 100 & 0 & 0 \\
\hline Animation & 100 & 0 & 0 \\
\hline Schedule & 100 & 0 & \\
\hline
\end{tabular}

Below are the most significant results on the role of ICTs in the educational context obtained from Likert scale the degree of agreement with certain statements (see Table 3). These data allow to conclude about the importance of using ICT in the teaching / learning as well as the possible advantages and drawbacks of its use both by teachers and by students of this program and in the field of training not regulated so that it helps to acquire the skills and planned objectives. Specifically, the Internet and the use of viewing videos used in the program were a technological resource EMFE especially motivating for participants in the program both for students and faculty. Modules were taught the basics of computer literacy so that students can computerize your resume, your cover letter, etc. and facilitate and guide for access to different websites both more general and more specialized for searching employment. In fact, some students called him from temporary employment to join the working world exactly some of those jobs that had demanded and sought after by those websites to which they agreed for career guidance modules. 
Table 3. Internet functions in the educational context (\%).

\begin{tabular}{|l|c|c|c|c|}
\hline & Nothing & Little & Enough & A lot \\
\hline 1. The internet can be used to teach & 0 & 0 & 74.18 & 25.82 \\
\hline 2. The internet can replace the teacher's role & 32.46 & 67.54 & 0 & 0 \\
\hline $\begin{array}{l}\text { 3. Internet only know how to use the higher level students with intel- } \\
\text { lectual }\end{array}$ & 35.71 & 42.86 & 21.43 & 0 \\
\hline 4. Internet can replace the role of books and whiteboards & 14.28 & 57.14 & 28.57 & 0 \\
\hline $\begin{array}{l}\text { 5. Internet can combine with the explanations that the teacher per- } \\
\text { forms in slate }\end{array}$ & 0 & 7.14 & 78.57 & 14.28 \\
\hline $\begin{array}{l}\text { 6. It would be more useful, fun and rewarding learning through the } \\
\text { Internet }\end{array}$ & 0 & 25.81 & 61 & 13.39 \\
\hline 7. Positive values are transmitted on the Internet & 8.29 & 74.28 & 17.43 & 0 \\
\hline $\begin{array}{l}\text { 8. Internet can only be used today in areas socioeconomically privi- } \\
\text { leged }\end{array}$ & 6.93 & 52.41 & 30.86 & 9.80 \\
\hline $\begin{array}{l}\text { 9. The socioeconomic status of families that we know influence } \\
\text { Internet }\end{array}$ & 0 & 0 & 61 & 39 \\
\hline 10. Internet fosters the ability to relate to others & 0 & 51.47 & 48.53 & 0 \\
\hline 11. Promotes the use of other languages & 0 & 43.69 & 56.31 & 0 \\
\hline $\begin{array}{l}\text { 12. It doesn't work on improving the relationship between members of } \\
\text { the Educational Community }\end{array}$ & 12.29 & 58.45 & 29.26 & 0 \\
\hline $\begin{array}{l}\text { 13. The teacher - student relationship is lost internet } \\
\text { 14. Peer relationships are lost with the use of the internet }\end{array}$ & 11.58 & 34.69 & 53.73 & 0 \\
\hline 15. Using the Internet helps to make new friends & 0 & 39.27 & 52.76 & 0 \\
\hline 16. Using the Internet isolates people in their environment & 51.14 & 9.86 \\
\hline
\end{tabular}

Impact and Satisfaction with Major Socio-Orientation Activities Conducted in the Program EMFE

Below are the results of descriptive analysis made from the interesting information from interviews and opinion polls carried out on the main achievements of labor integration and the impact and satisfaction with major socio-orientation activities conducted in the program EMFE. In this sense, it is important to note that the opinion poll, conducted interviews and questionnaires to learn about positive and negative aspects of the program allowed us to conclude that the vast majority of the participants both teachers (100\%) and students (99\%) showed a very high degree of satisfaction with the program and felt that they would like to continue in it. They are also very significant achievements and learnings achieved in each of the specialties.

From this moment began to find work and many were raised soon after paid work related to the specialty especially in carpentry and local self-employment, so we can say that there was a significant percentage of job placement as discussed in the next section. Then in Tables 4 and 5 show some of the many facts that can be extracted and satisfaction referring to the impact the program has had on the participating pupils. 
PROBLEMS

OF EDUCATION

IN THE $21^{\text {st }}$ CENTURY

Volume 44, 2012

Table 4. Satisfaction (\%) of students participating in some of the activities in the Mixed Experiences Program of Training and Employment.

\begin{tabular}{|c|c|c|c|c|}
\hline & Unsatisfactory & Something satisfying & Quite satisfying & Very satisfactory \\
\hline & $\%$ & $\%$ & $\%$ & $\%$ \\
\hline Travelling training & 0 & 0 & 5 & 95 \\
\hline Employment sites & 0 & 0 & 28 & 72 \\
\hline Conferences & 0 & 0 & 16 & 71 \\
\hline Group activities & 0 & 0 & 24 & 84 \\
\hline Video viewing & 0 & 0 & 0 & 76 \\
\hline Orientation & 0 & 0 & 0 & 100 \\
\hline Tutoring & 0 & 0 & & 100 \\
\hline
\end{tabular}

Table 5. Satisfaction (\%) of students participating in the Mixed Experience Program Training and Employment, in general terms.

\begin{tabular}{|c|c|c|c|}
\hline Unsatisfactory & Something satisfying & Quite satisfying & Very satisfactory \\
\hline$\%$ & $\%$ & $\%$ & $\%$ \\
\hline 0 & 0 & 3 & 97 \\
\hline
\end{tabular}

Overall, the qualitative and quantitative evaluation performed shows that this was a successful experience necessary and satisfactory to all participants, teachers, students, families of the participants and the environment in which it developed. In qualitative research techniques, among others, for example, the following results: In relation to the carpentry course participants since the end of the course worked in carpentry in the town of varying duration depending on the demands of the locality.

They also expanded their training to keep familiar and deepening the specialized or streamlined while the procedures are analyzed for the imminent launch of a cooperative in the town. Participants performed internships in occupations more or less related to learning the course excellently valuing the contribution, support and encouragement that they marked the completion of the course demonstrating the impact it has had important socio-emotional skills learned in the module Occupational guidance for achieving your first job, even in occupations directly related to the profession learned. From the beginning our youth knew that one of their main job opportunities could be the self, focusing the training and guidance that they gave this aspect also. In fact, telephone interviews at six months of completion allowed to note that the $99.49 \%$ consider training and self-employment as major elements (at a scale of $1=$ None, 2 $=$ Somewhat, $3=$ Fairly and $4=$ very much) as the main access road to the labor market with greater assurance of stability in employment.

Thus, many young Potter course who did not hesitate in trying to make their selfemployment as a way to access their first job with the consequent advantages so nuanced in the Vocational Guidance module. The students are highly satisfied with their participation in the Program, as evidenced by opinion polls carried out, both by the Bank as the other questionnaires / tests / instruments used by the Department. 
With regard to the assessment of key skills acquired by students, below in Table 6 shows to average score achieved by the total simple as Likert scale format $(1=$ Never and $5=$ Almost always).

Table 6. Competencies attained by students in the program reported by teachers EMFE teachers/ tutors practices.

\begin{tabular}{|c|c|}
\hline Competencies & Media (DT)* \\
\hline \multicolumn{2}{|c|}{ Technical skills } \\
\hline It is capable of performing the activities assigned & $4.89(.83)$ \\
\hline Apply appropriate techniques & $4.52(.65)$ \\
\hline Adapts easily to the work & $4.48(.58)$ \\
\hline Provides ideas for process improvement & $3.99(.59)$ \\
\hline Ends the work properly & $4.89(.51)$ \\
\hline \multicolumn{2}{|c|}{ Organizational skills } \\
\hline Attend punctually at the centre of the work & $4.90(.25)$ \\
\hline Is displayed neat and clean the productive process & $4.79(.37)$ \\
\hline Performs tasks on time & $4.84(.34)$ \\
\hline Knows how to work in groups & $4.69(.43)$ \\
\hline Has habits of works & $4.98(.35)$ \\
\hline \multicolumn{2}{|c|}{ Relational skills } \\
\hline Ask for information and help when she needs & $4.58(.51)$ \\
\hline Cooperates with others when needed & $4.53(.42)$ \\
\hline Integrates into the workgroup & $4.70(.33)$ \\
\hline Interacts with other departments, areas or specialties & $4.34(.38)$ \\
\hline Behaves like a mature person and accountable & $4.73(.43)$ \\
\hline \multicolumn{2}{|c|}{ Ability to respond to contingencies } \\
\hline Has initiative & $4.48(.59)$ \\
\hline Provides solutions to problems and ideas & $4.70(.40)$ \\
\hline Acts quickly on the contingencies & $4.60(.56)$ \\
\hline Use the tools & $4.86(.32)$ \\
\hline Reorganises work with diligence & $4.57(.51)$ \\
\hline
\end{tabular}

*DT= standard deviation

Following an assessment scale of 1 to 5 (from lower to higher degree of willingness to each factor) the total average score achieved by students in the general attitude factor is 4.6 course, in the attitude towards the method factor is 4.2 , attitude towards test is 3.9 and attitude towards the work load is 4.3. Regarding the assessment of the trainer achieved the average score for the same as reported by the students is 4.7 on efficiency and effectiveness in solving problems and 4.9 on the availability and attention given.

\section{Discussion}

In this study we have presented the structure and fundamental characteristics of the successful EMFE Program. It also examines what are the attitudes and interests towards ICT by students participating in the Program as an important element EMFE before making use of various technological means to facilitate the job placement process. It also provides an assessment of the impact and satisfaction of the major educational activities in this program. Subsequently, exhibit, in general terms, the main achievements reached labor integration that emerge from the quantitative and qualitative data collected in this regard.

This study provides an assessment of the impact and satisfaction of certain educational activities has had on the students participating in this program as protagonists of the teaching/ learning. The data show that the program has been a successful experience that has helped to facilitate labor insertion of participating pupils. One of the elements that today is considered 
PROBLEMS

OF EDUCATION

IN THE $21^{\text {st }}$ CENTURY

Volume 44, 2012

62

relevant in this type of program is achieving the overall strategic planning objectives (goal, monitoring and control). In this sense, the celebration of this program contributed, as predicted in previous planning objectives, to the students of this course to acquire the knowledge, skills and abilities necessary to develop the process of job placement. Although in this field, as is frequently reflected in the literature on Educational Psychology, Human Resources and Organizational (Gallego, 1999) we have no magic wands, it is important to evaluate how this program was considered aspects such as resources, interests, social and employment situation, motivation, skills, abilities, knowledge and social skills of students (Rivas, 1993; Sanchis, Pastor, Campos and Ibanez, 2002; Santana and Alvarez, 1996).

The data show positive attitudes in students towards the use of new technologies like the Internet to facilitate their learning and that most of the activities they have been very satisfactory. In developing the program has been used EMFE and application of new technologies to facilitate social and occupational integration and it is especially motivating technological resources for students of this age, still very useful even for learning certain important values to facilitate labor integration process (Javaloy, Espelt and Cornejo, 2001; Morales, Infante and Galindo, 2003). They claim these participants, generally speaking, computer skills are at the user level in terms of word processors, databases, spreadsheets and the Internet, while not claiming to have knowledge of graphic design, animation and programming. Thus, computers were used to introduce us websites to complete both the content and search for other employment. In this sense, used different software (regeneration strategy of technological resources). As found in current studies is relevant to have knowledge about computer use and attitudes towards ICT as those obtained in these work students of these ages (Ademola, 2009).

With regard to the impact assessment and satisfaction of career guidance activities undertaken, they are perceived as very useful and successful by students, faculty and families of participants recipients who are particularly grateful for the guidance and support social and labor welcome. Furthermore, the large percentage gains and labor integration achieved support the efficacy and efficiency of this important program.

Many participants in these programs, even the most intellectually brilliant, not just those at social disadvantage is the kind that is, those who need advice and assistance regarding the development of curriculum and preparation for job interviews overcome, study strategies, testing, ways of presenting information, and so on. With that assistance was provided to student learning that are supported based on their prior knowledge and their potential, without forgetting that social and labor-oriented activities should be carefully designed to help students understand themselves, their interests, values, skills, facilitating identification and resolution of problems.

From the perspective psychoeducational maintained in this program, we evaluated the characteristics of the deficit of certain persons (for example, there are certain characteristics that are usually present in certain people with disabilities) but above all, it was known to the person before whom we are advising, since each one is different and requires special attention and personalized tutoring.

\section{Conclusions}

In short, it is worth noting that this program has contributed to finding satisfactory solutions, efficient and effective the process of socialization and social integration through a more rewarding use of time for the individual and socially more useful in this process helping relationship. This was attempted in some way fit between personal characteristics of young (abilities, interests, personality, etc.) and the varied demands of work considering the job, tasks, functions and occupation as fundamental aspects or characteristics identified and analyzed, which are accentuated more or less depending on the core consultative approach.

Concerning the potential limitations of the present study, it is worth mentioning the 
recommendation, among others, of using deeper multivariate analyses in future studies, in order to reach more precise and solid conclusions.

Finally, we conclude that it is a pioneer program in that reported numerous benefits and social and labor opportunities for unemployed youth at risk of social exclusion, academically unmotivated and could not be easily incorporated into other programs.

The ongoing social demand for such programs in the current economic crisis supports its need for continuity and consistency to provide help and support youth in their social and labor integration process.

\section{Acknowledgements}

This program was funded by the Junta de Andalucía and the European Regional Development Fund (ERDF).

\section{References}

Ademola, R. (2009). Influencia de la ansiedad ante los ordenadores y el conocimiento de su uso en estudiantes de secundaria. [Influence of anxiety about computers and knowledge of its use in high school students]. Electronic Journal of Research in Educational Psychology, 19, 1269-1288.

Cohen, P. A. (1981). Students ratings of instruction and Student achievement: A meta-analysis of multisection validity studies. Review of Educational Research, 51, 281-309.

De Pablos, J. (2009). Tecnología educativa. La formación del profesorado en la era de Internet. [Educational technology. Teacher training in the Internet Age]. Málaga: Aljibe.

Gallego, S. (1999). Cómo planificar el desarrollo profesional. [How can you plan your professional development?]. Barcelona: Laertes.

Javaloy, F., Espelt, E. y Cornejo, J. M. (2001). Internet y movimientos sociales: un enfoque psicosocial. [Internet and social movements: a psychosocial approach]. Anuario de Psicología, 32, 31-37.

Marsh, H. W., Overall, J. V. y Kesler, S. P. (1979). Validity of Studentes evaluations of instructional effetiveness: A comparison of Faculty Self-Evaluations and Evaluations by their Students. Journal of Educational Psychology, 71, 149-160.

Martínez, T. y Aguaded, J. (2004). El uso de las TIC en alumnos principiantes de las universidades españolas. [The use of ICT in beginning students of Spanish universities]. Granada: GEU.

Morales, F. M., Infante, L. y Galindo, A. (2003). Actitudes e intereses hacia Internet en una muestra de estudiantes de Secundaria. [Attitudes and interests to Internet in a sample of high school students]. Encuentros en Psicología Social, 1, 3-6.

Rivas, F. (1993). Psicología Vocacional. Enfoques del asesoramiento. [Vocational Psychology. Advice approaches]. Madrid: Ediciones Morata, S. L.

Sanchis, P., Pastor, J., Campos, V. e Ibáñez, J. J. (2002). Curso de Formación para Agentes de Inserción Sociolaboral. [Agent Training Course Social and Labour Integration]. Universidad Nacional de Educación a Distancia. Valencia: Centro Alzira.

Advised by Milan Kubiatko, Masaryk University, Czech Republic

Received: May 04, 2012

Accepted: June 27, 2012

\begin{tabular}{|c|c|}
\hline $\begin{array}{l}\text { Francisco Manuel Morales } \\
\text { Rodríguez }\end{array}$ & $\begin{array}{l}\text { PhD in Psychology and Bachelor of Labour, Associate Professor (Doctor), } \\
\text { Department of Psychology and Education, School of Psychology, University } \\
\text { of Malaga, Campus de Teatinos s / n, 29071, Spain. } \\
\text { E-mail: framorrod@uma.es } \\
\text { Website: http://webdeptos.uma.es/psicoev/ }\end{array}$ \\
\hline
\end{tabular}

